\title{
Spatial Learning in the 5-HT1B Receptor Knockout Mouse: Selective Facilitation/Impairment Depending on the Cognitive Demand
}

\author{
Marie-Christine Buhot, ${ }^{1,4}$ Mathieu Wolff, ${ }^{1}$ Narimane Benhassine, ${ }^{1}$ Pierre Costet, ${ }^{2}$ \\ René Hen, ${ }^{3}$ and Louis Segu ${ }^{1}$ \\ ${ }^{1}$ Centre National de la Recherche Scientifique-Unité Mixte de Recherche 5106, Laboratoire de Neurosciences Cognitives, \\ Université de Bordeaux 1, 33405 Talence cedex, France; ${ }^{2}$ Laboratoire de Transgénèse, Université de Bordeaux 2, 33076 Bordeaux \\ cedex, France; ${ }^{3}$ Center for Neurobiology and Behavior, Columbia University, New York, New York 10032, USA
}

\begin{abstract}
Age-related memory decline is associated with a combined dysfunction of the cholinergic and serotonergic systems in the hippocampus and frontal cortex, in particular. The 5-HTIB receptor occupies strategic cellular and subcellular locations in these structures, where it plays a role in the modulation of $\mathrm{ACh}$ release. In an attempt to characterize the contribution of this receptor to memory functions, 5-HTIB receptor knockout (KO) mice were submitted to various behavioral paradigms carried out in the same experimental context (water maze), which were aimed at exposing mice to various levels of memory demand. 5-HTIBKO mice exhibited a facilitation in the acquisition of a hippocampal-dependent spatial reference memory task in the Morris water maze. This facilitation was selective of task difficulty, showing thus that the genetic inactivation of the 5-HTIB receptor is associated with facilitation when the complexity of the task is increased, and reveals a protective effect on age-related hippocampal-dependent memory decline. Young-adult and aged KO and wild-type (WT) mice were equally able to learn a delayed spatial matching-to-sample working memory task in a radial-arm water maze with short ( 0 or $5 \mathrm{~min}$ ) delays. However, 5-HTIBKO mice, only, exhibited a selective memory impairment at intermediate and long $(15,30$, and 60 min) delays. Treatment by scopolamine induced the same pattern of performance in wild type as did the mutation for short (5 min, no impairment) and long (60 min, impairment) delays. Taken together, these studies revealed a beneficial effect of the mutation on the acquisition of a spatial reference memory task, but a deleterious effect on a working memory task for long delays. This 5-HTIBKO mouse story highlights the problem of the potential existence of "global memory enhancers."
\end{abstract}

Data from cognitive psychology, neuropsychology, and behavioral neuroscience no longer conceive memory as a unitary process (e.g., Cohen and Squire 1980; Cohen 1984; Graf and Schacter 1985; Kesner 1986; Tulving 1987). Based on neuropsychological studies in humans, different memory systems have been defined on the basis of (1) the cognitive operations that they enable and (2) the structures of the central nervous system that are implicated therein. In the declarative system, long-term memory ensures the consolidation of information for long-term retrieval or recognition, and short-term memory allows the maintenance of information during short periods of time to execute a particular action or sequential actions (Baddeley 1995). Studies in humans may not be directly applicable to rodents. However, there may be some homologies that experiments in rodents reveal. Hence, if the hippocampus is conceived as a key structure involved in long-term, especially spatial memory (O'Keefe and Nadel 1978), but also in working memory (Olton et al. 1979), the prefrontal cortex is also considered as a key structure to complete working memory tasks (Fuster 1989; Tulving 1991), especially those that are sensitive to interferences.

In humans as well as animals, memory performance is altered during aging. Age-related memory impairments have been mainly attributed to the progressive degeneration of the cholin-

\section{${ }^{4}$ Corresponding author.}

E-MAIL buhot@neurocog.u-bordeaux.fr; FAX (33) 540008743. Article and publication are at http://www.learnmem.org/cgi/doi/10.1101/ Im.60203. ergic system (Kasa et al. 1997; Tune and Sunderland 1998; Sirvio 1999; Auld et al. 2002). They are, however, correlated to a combination of disturbances in both cholinergic and serotonergic functions (Richter-Levin and Segal 1993; Meltzer et al. 1998).

Knowledge of the mechanisms by which serotonin (5-hydroxytryptamine, 5-HT) contributes to learning and memory requires an in-depth investigation of the role played by specific types or subtypes of 5-HT receptors, especially those localized in particular cerebral structures underlying defined cognitive functions. Besides the pharmacological approach, which attempts to evaluate the behavioral functions of particular receptors by the use of specific drugs, molecular genetic techniques provide useful complementary tools, in particular knockout (KO) mice with a deletion of a single gene coding for a specific receptor, which constitute unique models of selective dysfunctions.

The aim of the present contribution is to review recent neurobiological and behavioral data showing how 5-HT, via the 5-HT1B receptor, is able to modulate memory systems, in particular by its interaction with the cholinergic system. This review focuses on the strategy of our laboratory, which has used the 5-HT1BKO as a biological model for behavioral investigations.

Neurobiological Bases of the Contribution of Serotonin to Memory: The 5-HT1B Receptor as a Key Receptor

\section{5-HT in Memory: Basic Neurobiological Data}

Serotonin is involved in a large spectrum of physiological functions, including higher-order cognitive functions. The glutama- 
tergic and cholinergic neurotransmitter systems are crucially involved in memory formation, but there is increasing evidence showing that 5-HT functionally interacts with these systems, and thereby is able to play a modulatory role in memory functions (Fig. 1; Buhot 1997; Buhot et al. 2000, 2003b).

Serotonergic projections from the raphe nuclei, where 5-HT cell bodies are concentrated, are widespread and terminate in brain structures thought to underlie memory processes such as the hippocampus, the prefrontal cortex, cortical associative areas, basal ganglia, or thalamus. The projections to the hippocampus arise mainly from the median and dorsal raphe nuclei (MRN and DRN, respectively), with the former reaching the dorsal and median hippocampus, and the later reaching the ventral hippocampus (Azmitia and Segal 1978), with possible consequences for hippocampal-dependent memory functions. Neurogenesis in the dentate gyrus of adult rats may be associated with the formation of some types of hippocampal-dependent memories (Gould et al. 1999; Shors et al. 2002). Depletion of 5-HT with 5,7-dihydroxytryptamine (5,7-DHT) reduces neurogenesis, thus serotonin might be a factor stimulating granule cell production (Brezun and Daszuta 1999). If a large body of evidence has been accumulated concerning mechanisms of so-called hippocampal-dependent memory, much less is known on the way serotonin controls the prefrontal cerebral cortex, and consequently may contribute

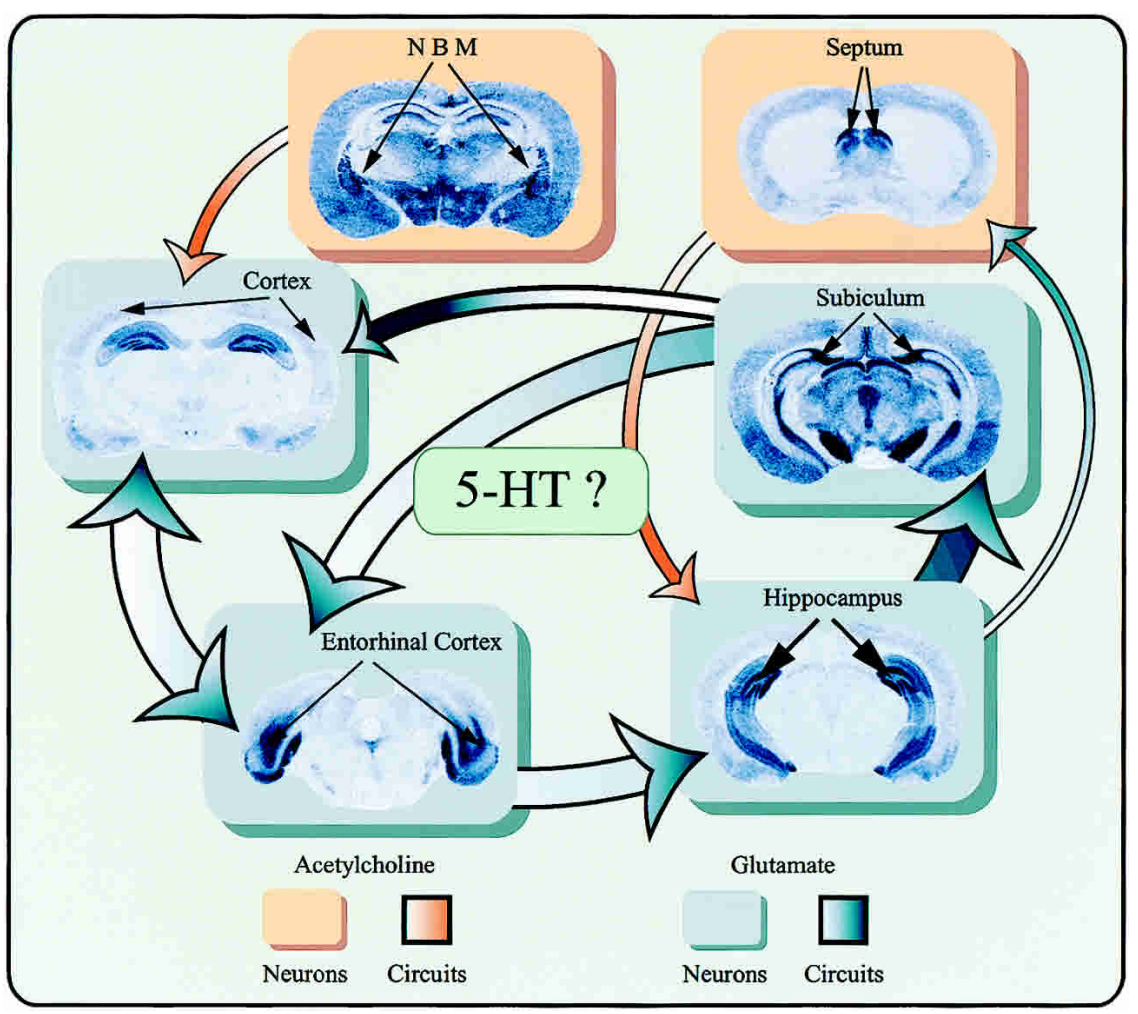

Figure 1 Schematic representation of the main cerebral circuits underlying spatial memory. Information from the external environment reaches cortical areas (Cortex) from where they are carried, through the entorhinal cortex, to be processed by the hippocampus. The product of intrahippocampal processing is sent to the Subiculum and to cortical areas (Cortex). This corticohippocampo-cortical communication allows for the consolidation of information into long-term memory. These pathways (in blue) are glutamatergic in nature. Cholinergic afferences (in orange) from the nucleus basalis magnocellularis (NBM) and the septum-diagonal band of Broca (Septum) exert an excitatory regulation on this circuit. The question is then, how does serotonin modulate these communications and thus play a role in learning and memory? (5-HT?). Each anatomical structure is signaled by black arrows on autoradiograms of brain sections labeled for the 5-HT1A receptor (e.g., Hippocampus) and the 5-HT1B receptor (e.g., Subiculum; adapted from Buhot et al. 2003b). to its role in the organization of short-term/working memory. However, some data indicate that serotonin has also a significant modulatory influence on the functional activity of the prefrontal frontal cortex predominantly originate in the DRN and establish (as free terminals) contacts throughex glutamatergic cortical neurons, and of their tacts (Wilson and Molliver 1991). DRN-prefrontocortical serotonergic depletion, using 5,7-DHT, was observed to induce facilitation in a short-term memory task in rats, associated with cytoarchitectural alterations in cortical pyramidal cells, a result that lated" excitatory cholinergic activity due to 5-HT depletion erez-Vega et al. 2000). Thus, among possible mechanisms linking 5-HT to memory, the interaction with the cholinergic system stitutes a key factor.

transmission induces persistent memory impairments in rat, as compared with the loss of cholinergic transmission alone inergic muscarinic receptor antagonism and 5-HT depletion induce severe deficits in spatial performance of rats (Harder et al. 1996), but part of these deficits may be linked to noncognitive, that is, sensorimotor, dysfunctions (Beiko et al. 1997). Intrahippocampal cografts of fetal cholinergic and serotonergic neurons are able to reduce impairments in long-term spatial memory induced by extensive lesions of the dorsal septo-hippocampal pathways (Balse et al. 1999). 5-HT modulates the activity of cholinergic septo-hippocampal neurons, either directly (Milner and Veznedaroglu 1993) or indirectly via modulation of the activity of GABAergic interneurons in the medial septum (Farr et al. 1999). Taken together, these data indicate that the functional interaction between ACh and 5-HT systems plays an important role in learning and memory performance (Cassel and Jeltsch 1995; Steckler and Sahgal 1995).

\section{Strategical Cellular and Subcellular Locations of the 5-HTIB Receptor: Memory-Related Functions?}

There are at least two main criteria that have to be taken into account to analyze the potential role played by a receptor in a function such as memory: (1) its linkage to a second messenger and (2) its anatomical, cellular, and subcellular locations in the central nervous system.

The 5-HT1B receptor is a member of the seven transmembrane domain receptors family (Bockaert and Pin 1999), and is linked to a guanine nucleotide-binding protein $(G)$, the Gi protein, so that activation of this receptor results in the decrease in adenylyl cyclase (AC) activity, and consequently in inhibitory effects at the intracellular level. This coupling depends on the neuron type. As an example, in tissues containing $\mathrm{Ca}^{2+}$-insensitive adenylyl cyclases (e.g., type II), the 5-HT1B receptor stimulates the activity of the enzyme. This acti- 
vation is due to the $\beta-\gamma$ subunits released from activated proteins Gi (Albert et al. 1999). A single receptor subtype can also be linked to multiple effector pathways within a cell (Marinissen and Gutkind 2001). Native 5-HT1B expressed in OK (opossum kidney) cells are coupled to both elevation of intracellular calcium and inhibition of adenylyl cyclase (Zgombick and Branchek 1998). Activation of recombinant h5-HT1B and h5-HT1D in C6 glioma cells produces increases in $\mathrm{Ca}^{2+}$-dependent $\mathrm{K}^{+}$current (Le Grand et al. 1998).

Each type or subtype of serotonin receptor has a specific regional distribution in the brain (Hoyer and Martin 1997). The possibility that a 5-HT receptor plays a role in memory functions resides on the evidence that this receptor is present in crucial regions underlying these functions. This is the case of the 5-HT1B receptor that is found in the hippocampus, the dorsal subiculum, and the frontal cortex, in particular (Boschert et al. 1994; Sari et al. 1997). In terms of cellular location (or neuron type), the 5 -HT1B receptor mRNA and proteins are present on the cholinergic septo-hippocampal pathway, on glutamatergic pyramidal cells in the CA1, and on GABAergic interneurons in different regions (Boschert et al. 1994). In terms of subcellular location (or compartment), the 5-HT1B receptor is predominantly located on axon terminals, where it directly inhibits the release of neurotransmitter, owing to its negative linkage to adenylyl cyclase. A noticeable property of the 5 -HT1B is to present an anatomical dissociation between the location of the mRNA and the protein receptor (Boschert et al. 1994). As an example, mRNAs have been localized in CA1 pyramidal cells in the hippocampus, whereas the corresponding 5-HT1B protein receptors have been localized in the subiculum (for demonstrations, see Aït Amara et al. 1995, 2001). As an autoreceptor, it is located on 5-HT terminals, and controls the release of 5-HT in the brain. This receptor subtype is thus present in the different projection areas with regard to the raphe nuclei, in particular those involved in cognitive functions, such as the septum, hippocampus, the NBM or the entorhinal and frontal cortices, but also the ones underlying, for example, locomotor functions, such as the substantia nigra. As an heteroreceptor, it controls the release of other neurotransmitters, such as glutamate in the subiculum, GABA in the frontal cortex, and acetylcholine (ACh) in the hippocampus (Fig. 2).

We demonstrated that intrahippocampal stimulation of 5-HT1B receptors, by the specific 5-HT1B receptor agonist CP 93129, impairs the performance of rats trained in a radial arm maze using a procedure that enables to dissociate working from reference memory errors. This impairment affected the reference memory component of the task more than the working memory component (Buhot et al. 1995). These results might be explained by the specific cellular and subcellular locations of 5-HT1B receptors in the hippocampal formation (Sari et al. 1997). Stimulation of 5-HT1B receptors located on axon terminals of glutamatergic CA1 pyramidal cells (Aït Amara et al. 2001) decreases the release of glutamate, reducing thereby CA1-subiculum transmission (Boeijinga and Boddeke 1996). Thus, 5-HT, via 5-HT1B receptors, may modulate via a kind of filter function, the transfer of processed information from the hippocampus to cor- tical areas. Furthermore, 5-HT1B heteroreceptors modulate the release of ACh in the hippocampus and the frontal cortex (Fig. 2; Maura and Raiteri 1986; Izumi et al. 1994; Cassel et al. 1995; Consolo et al. 1996). How far may these processes influence either time-dependent (dynamic of the memory trace) or task-dependent (memory systems) functions, or both? The present review was also aimed at contributing to answer these questions on the light of behavioral investigations using the 5-HT1BKO mouse (Saudou et al. 1994).

\section{What Does the 5-HTIBKO Mouse Tell Us About the Role Played by Serotonin in Learning and Memory? The 5-HTIBKO Mouse Exhibits Enhanced Spatial Memory Performance in the Morris Water Maze}

The fact that stimulation of hippocampal 5-HT1B receptors results in impaired spatial learning in rats (Buhot et al. 1995) indicated that the inactivation of 5-HT1B receptors might have positive effects on hippocampal-dependent learning and memory processes.

We adopted a molecular biological strategy for studying the implication of 5-HT1B receptor in memory by using 5-HT1B receptor knockout (5-HT1BKO) mice (Saudou et al. 1994) as subjects submitted to various behavioral paradigms, such as the Morris water maze (Morris 1984), that do not require food deprivation, because the 5-HT1B receptor is involved in food intake (Lee and Simansky 1997).

Both wild-type and 5-HT1BKO mice equally learned to attain the visible platform in a relatively efficient manner. During the first stage of spatial learning using the hidden platform, both groups of mice improved their performance across days. However, the different measures of performance indicated that $\mathrm{KO}$

\section{Learning \& Memory}

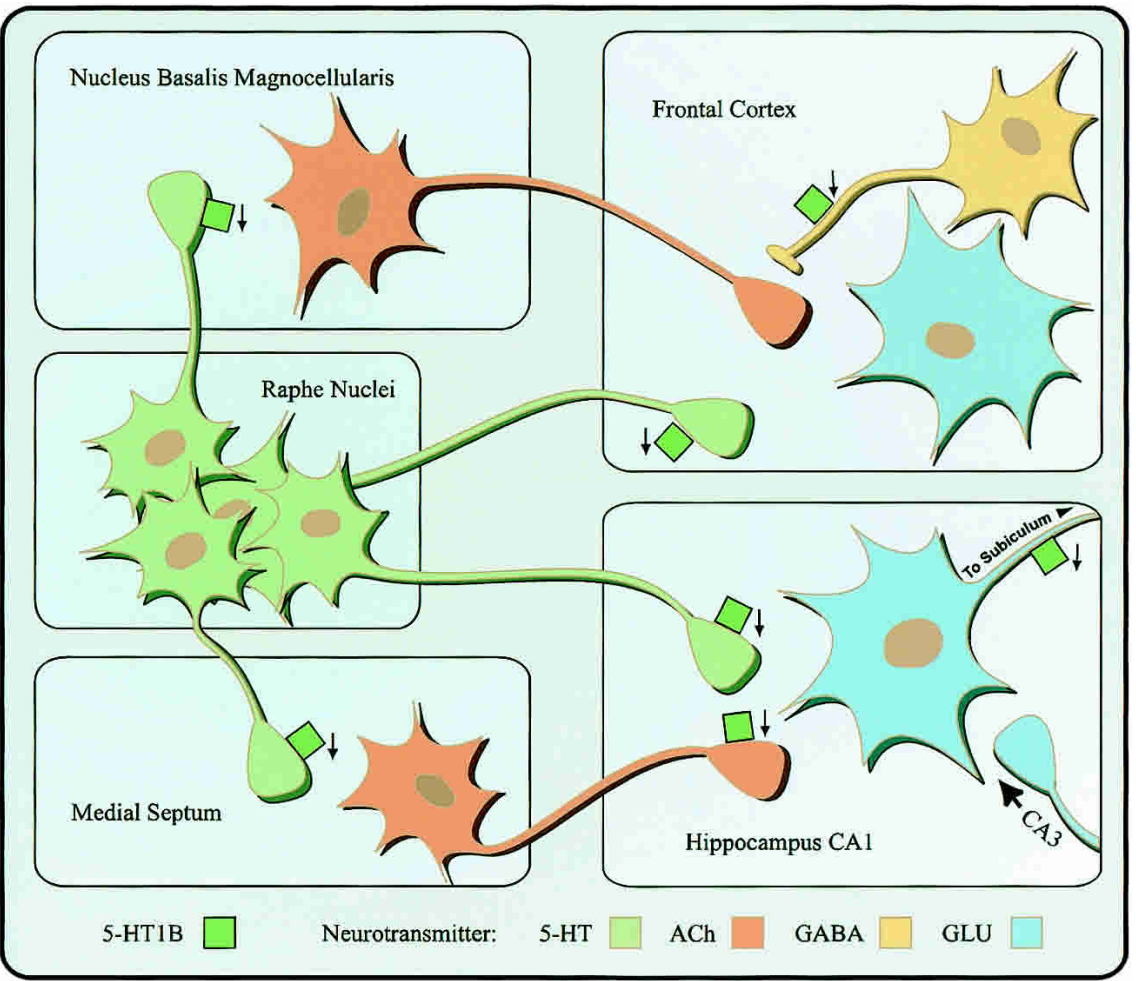

Figure 2 Localization of the 5-HT1B receptor in different neuronal membrane compartments of the septo-hippocampal and basalo-cortical complexes. Schematic representation of data obtained by different authors by using electrophysiology, microscopy, and neurotransmitter release methods. The functional consequences of the activation of the 5-HT1B receptor are indicated by downward arrows for its inhibitory effect on the target neuron. See text for further explanation. 
mice performed the task more efficiently than wild-type mice (escape latency, $P<0.0005$; path length, $P<0.001$ ). After the displacement of the platform (transfer stage), both groups of mice learned its new location; but KO mice showed a facilitation (escape latency, $P=0.0001$; path length, $P<0.01$ ). During the probe trials following both the acquisition and the transfer stages, both wild-type and $\mathrm{KO}$ mice exhibited a significant bias while searching in the previous platform locations. Thus, at the end of the transfer, wild-type did not differ from $\mathrm{KO}$ mice in their accurate memory for the location of the platform. The strategies of spatial orientation in wild-type and $\mathrm{KO}$ mice changed according to the stages of learning. The trajectories clearly illustrate the increasing efficiency of the mice in finding the hidden platform, with $\mathrm{KO}$ mice exhibiting earlier direct trajectories to the platform (Fig. 3). More details are provided in the original publication (Malleret et al. 1999).

KO exhibited higher global exploratory activity than wildtype mice in the Y-maze $(P<0.001)$ and in an open field in the presence of objects $(P=0.05)$. However, locomotor activity as measured in an activity cage or in an empty open field did not show any genotype effect. The alternation rate measured in the Y-maze was as high in $\mathrm{KO}$ as in wild-type mice (95\% on average), thus revealing identical and efficient working memory abilities. Anxiety levels were found to be similar in wild-type and 5-HT1BKO mice as assessed in the elevated plus maze, as previously observed using another model of anxiety, that is, the light/ dark choice test (Ramboz et al. 1996). Furthermore, the mutation did not affect the ability to perform either the cue or the contextual fear-conditioning (see details in Malleret et al. 1999).

The main finding of this study is that the deletion of a single gene coding for a particular 5-HT receptor, the 5-HT1B, is associated with facilitation of learning abilities, without affecting general emotional state, locomotor abilities or simple association tasks. Interestingly, an independent study observed that the same 5-HT1BKO mice display longer periods of paradoxical sleep (Boutrel et al. 1999). Given the facilitatory influence of paradoxical sleep on memory consolidation (Hennevin et al. 1995), this result is in accordance with the long-term facilitation observed here.

Wild-type and $\mathrm{KO}$ mice also differed in locomotor/exploratory activity, but only when the environment was relatively "rich" given its internal structure (Y-maze) or the addition of inner variety (objects in the open field). This dissociation between locomotor and more cognitive components of the mouse's behavior indicates that "shyness," a characteristic of 129/Sv mice, is reduced in $\mathrm{KO}$ mice that respond more positively to novelty. The high level of reactivity to the environment exhibited by the KO mice can be brought together with the observation that the same mice exhibit increased pattern of prepulse inhibition, which may reveal elevated attentional capacities, at least at the sensorimotor level (Dulawa et al. 1997). This attentional component cannot be neglected in the analysis of learning and memory abilities of 5-HT1BKO mice. Another possibility is that KO mice could reveal a lower level of behavioral inhibition, which may indicate the presence of some aspect of impulsive behavior. However, if the KO mice exhibit impulsive behavior in a social context (aggression toward male intruders; Saudou et al. 1994), they do not clearly exhibit impulsive reactions in foodreinforced instrumental learning (Brunner and Hen 1997), but they are more motivated to self-administer cocaine (Rocha et al. 1998).

The effects observed in the present study might be explained by compensatory mechanisms due to the mutation. Autoradiographic analyses showed no difference in 5-HT1D and 5-HT1A binding site densities between brains of wild-type and 5-HT1BKO mice (Malleret et al. 1999). KO mice showed no adaptive changes
WILD TYPE

5HT1B KO

DAY 1
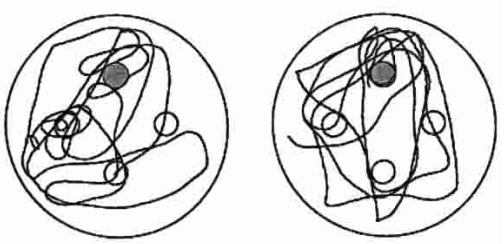

DAY 6
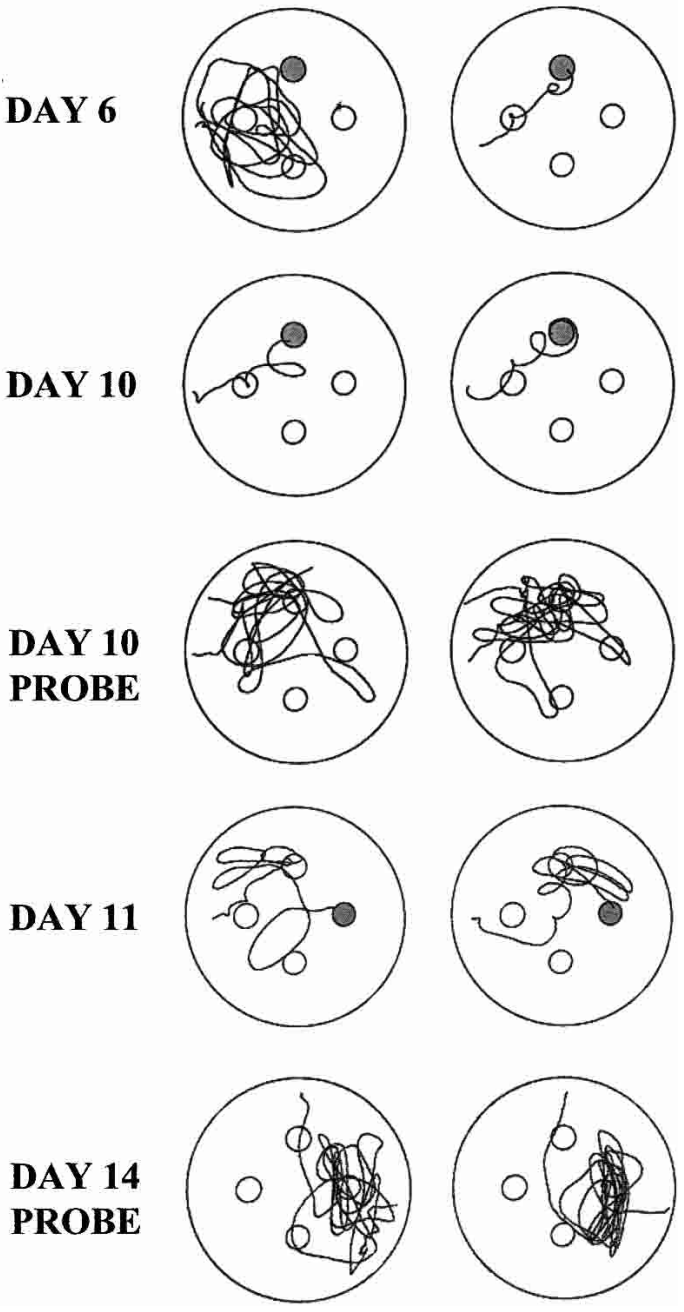

Figure 3 Representative trajectories of a wild-type (left) and a 5-HT1BKO (right) mouse during the various stages of the water-maze experiment using the spatial reference memory protocol. The presence of the platform is represented by a gray circle. On days 1, 6, and 10, the platform was located north (top of the schemas); on day 11 (first day of transfer), it was located east.

in 5-HT1A receptor function as measured by body temperature and heart rate responses (Bouwknecht et al. 2002). Furthermore, basal extracellular 5-HT levels, as measured by in vivo microdialysis, were found to be similar in the hippocampus and medial prefrontal cortex (mPFC) of both genotypes (Gardier et al. 2003). However, using a pharmacological challenge, a case of mutationrelated adaptation in 5-HT1BKO mice has been demonstrated concerning 5-HT2C receptor-mediated food intake and locomotor activity (Clifton et al. 2003).

\section{The 5-HTIBKO Mouse Exhibits Delayed Age-Related Memory Decline}

The functional integrity of the hippocampus and related structures, which are crucial for learning and memory, is particularly 

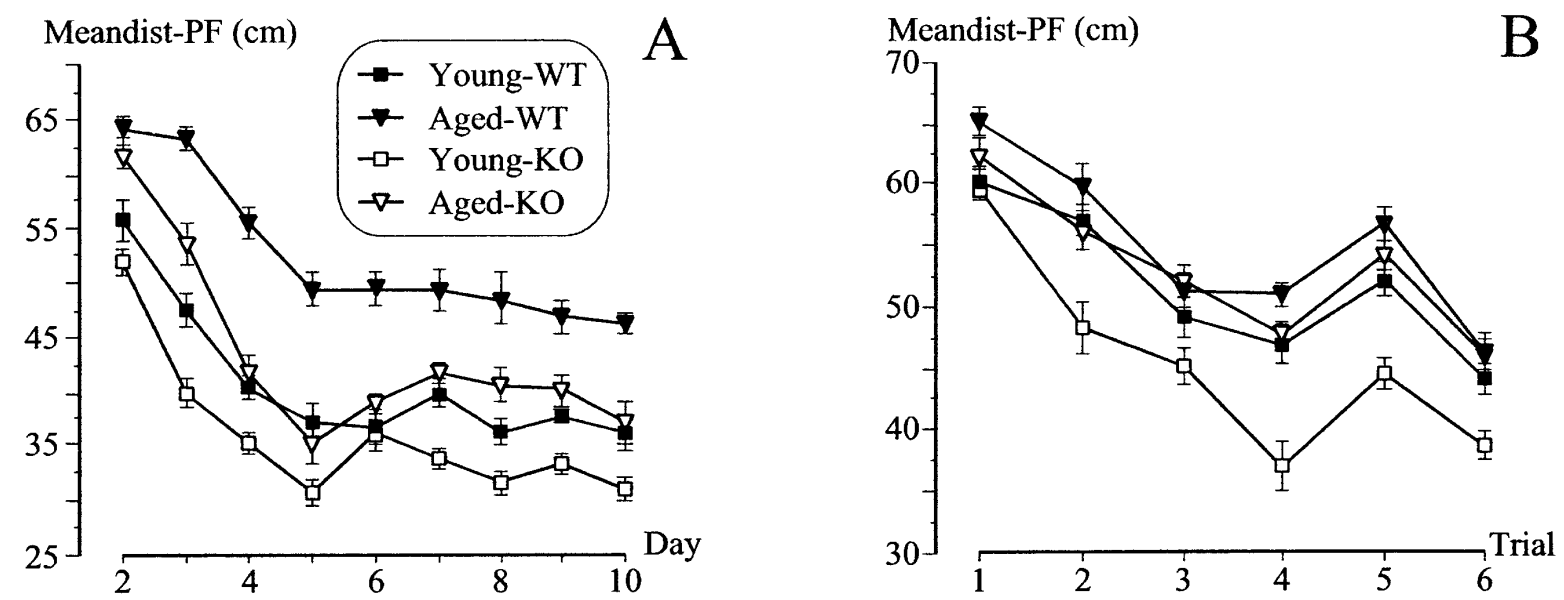

Figure 4 Performance in spatial learning of young-adult (Young: 3-mo-old) and aged (Aged: 22-mo-old) wild-type (WT) and 5-HT1BKO (KO) mice. $(A)$ Reference memory learning; mean ( \pm SE) distance of the subject to the platform, Meandist-PF $(\mathrm{cm})$ across days (days 2-10). (B) Massed learning; mean $( \pm \mathrm{SE})$ distance of the subject to the platform, Meandist-PF (centimeters), across trials (Trials 1-6).

vulnerable to the aging process (Bach et al. 1999; Foster 1999). The pharmacological strategies that are being pursued in Alzheimer's disease $(\mathrm{AD})$ research aim to reduce memory deficits that are mainly attributed to the progressive degeneration of the basal forebrain cholinergic system (Tune and Sutherland 1998; Sirvio 1999). However, reduced serotonin level is also a marker for accelerated cognitive decline in AD (Lai et al. 2002). Age-induced cognitive dysfunctions are correlated to a combination of disturbances in cholinergic and serotonergic functions (Richter-Levin and Segal 1993; Meltzer et al. 1998). Cholinergic muscarinic receptor antagonism and 5-HT depletion induce severe deficits in spatial performance of rats (Harder et al. 1996; Beiko et al. 1997) that tacrine, an acetylcholinesterase (AChE) inhibitor that has shown some potential in the treatment of cognitive symptoms of $\mathrm{AD}$, is able to counteract (Harder and Kelly 1997).

The present study evaluated whether the facilitation observed in adult (5-mo-old) 5-HT1BKO mice in long-term spatial memory performance would evolve with age. More precisely, we wanted to determine whether age-related deficits in learning performance would be attenuated by inactivation of the 5-HT1B receptor. To study the role of the 5 -HT1B receptor in age-related memory decline, we compared the spatial learning performances of young-adult (3-mo-old) and aged (22-mo-old) 5-HT1BKO and wild-type mice in the hidden platform protocols of the watermaze task assessing either long-term reference memory, or shortterm massed learning as described previously (for more details, see Buhot et al. 2003a).

Both wild-type and $\mathrm{KO}$ mice, independently of their age, rapidly learned to locate a visible platform, thus attesting that aged mice had preserved basic sensori-motor skills. All mice also acquired the reference memory task as indicated by the decrease of all performance parameters, that is, escape latency and path length, and in particular the mean distance of the subject to the platform (meandist-PF, in centimeters; ${ }^{5}$ Fig. $4 \mathrm{~A}$ ). This measure of performance, indeed, revealed significant effects of age

\footnotetext{
${ }^{5}$ This measure corresponds to the accumulated distance between the subject and the center of the platform, averaged on the number of record units (every $40 \mathrm{msec}$ ). Meandist values are particularly useful in that they are totally independent of the latency, thus of the swim speed. A low value of meandist-PF emphasizes spatial strategies characterized by correct initial orientations toward the platform, which minimize the distance between the subject and the goal.
}

$\left(F_{(1,38)}=160.91 ; \quad P<0.0001\right)$ and genotype $\left(F_{(1,38)}=83.81 ;\right.$ $P<0.0001)$. Young-adult mice swam closer to the platform than aged mice, as well as $\mathrm{KO}$ mice as compared with wild-type mice. As illustrated in Figure 4A, aged wild-type mice exhibited the greatest impairment, whereas young-adult $\mathrm{KO}$ mice exhibited the best performance. Aged 5-HT1BKO mice performed as well as young-adult wild-type mice. The other measures of performance (escape latency and path length) also revealed such age and genotype effects (all $P s<0.0001$ ). This effect of the mutation is interesting in the context of age-dependent memory dysfunctions.

In the short-term massed learning paradigm, the hidden platform was placed in a new location each day, and the mouse had six successive trials (from different start points) to improve its performance, which was evaluated across trials (averaged over the five daily sessions). Mice decreased their distance to the platform location from trial 1 to trial 6 (Fig. 4B). KO mice exhibited superior performance than wild-type mice $\left[F_{(1,38)}=17.46\right.$; $P=0.0002]$, and this was true in young-adult $\left[F_{(1,22)}=19.00\right.$; $P=0.0003]$, but not in aged mice. Similar results were observed considering escape latency $(P<0.05)$, but not path length. In this task, a dissociation was observed between the effects of age and of the mutation: the age effect affected more KO than wild-type mice, and the effect of the mutation affected young-adult mice only (Fig. 4B).

Taken together, these data show that the age effect interfered with the mutation in a way depending on the requirement of the task. Aging affected more wild-type mice and less KO mice in the reference memory task, whereas the opposite was observed in the massed learning. The reference memory version of the water-maze task reveals larger age-related deficits in rats than a working memory version of the task (Lindner et al. 1992), a result that is consistent with our present results in mice. In our study, we did not observe a clear age-related change in performance of wild-type mice in short-term massed learning. As for rats, this test has a lower capacity for discriminating age-related impairments. One aspect of this task is linked to the reduction of the intertrial interval, which facilitates learning and which, as a possible consequence, reduces cognitive demand. According to the task used, age-associated cognitive deficits are revealed or not. It is thus not so simple to assess the effect of age in rodent models (Gallagher and Pelleymounter 1988; van der Staay 2002). This is the reason that it seemed important to determine the nature of the cognitive facilitation observed in 5-HT1BKO mice. 
The 5-HTIBKO Mouse Exhibits a Selective Cognitive Facilitation When the Complexity of the Task Is Increased As demonstrated in the two preceding sections, 5-HT1BKO mice exhibit better spatial reference memory performance in the Morris water maze than their wild-type controls, and this beneficial influence still persists during aging. The present study was aimed at dissecting the underlying cognitive bases of this facilitation using a stepwise water-maze paradigm (Granon and Poucet 1995).

The first stage of this task was a simple orientation toward a fixed hidden platform (located east) from a single peripheral start position (north; days 1-6). Both wild-type and KO mice decreased their latencies and path lengths across successive days (Fig. 5A) without showing any genotype difference. However, swim speed was higher in KO than in wild-type mice $(P<0.0001$;
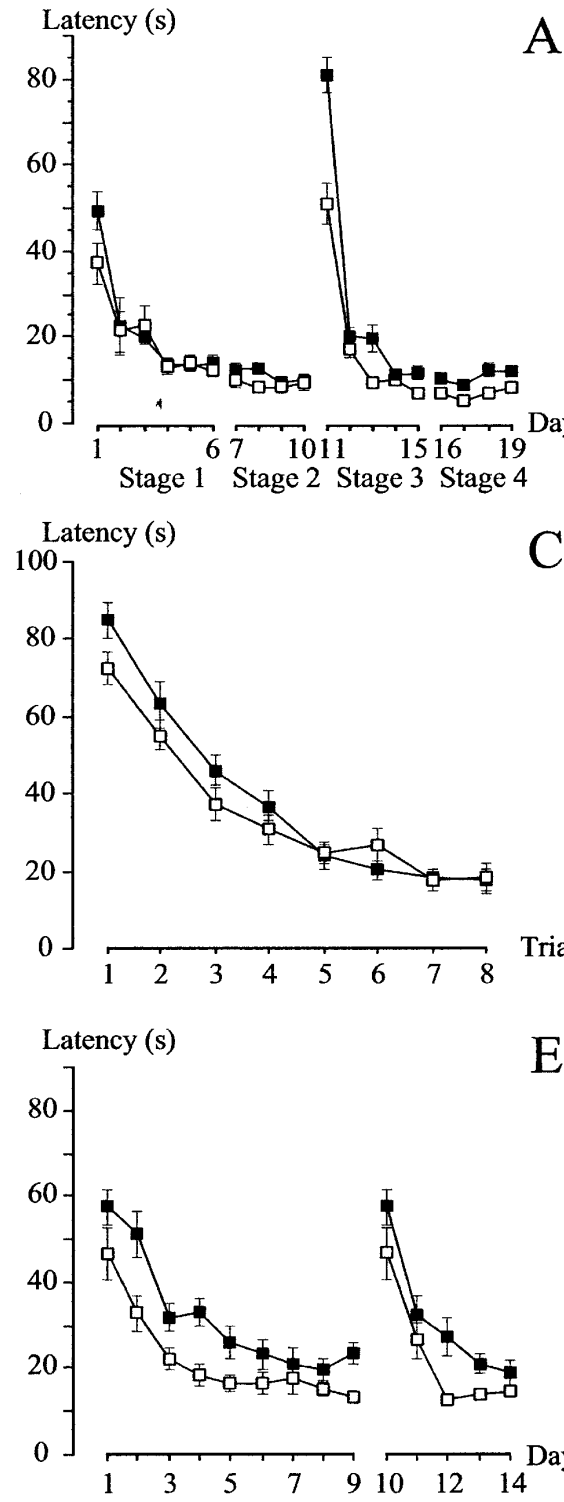

Figure 5 Performances in spatial learning of wild-type (WT) and 5-HT1BKO (KO) mice. $(A, B)$ Stepwise learning: performance across days during the first (1-6), second (7-10), third (11-15), and fourth (16-19) stages. $(C, D)$ Massed learning: performance across trials (1-8) averaged on 5 d. $(E, F)$ Standard reference memory learning: performance during the acquisition stage (1-9) and the transfer stage (10-14). ( $A, C, E)$ Mean ( $\pm S E$ ) latency to reach the platform (in seconds); $(B, D, F)$ mean ( \pm SE) swim speed (centimeters/second).
Fig. 5B). The second stage involved an additional opposite $\left(180^{\circ}\right.$ apart) start position (south), without any change in the platform position (days 7-10). This stage, which required the use of an allocentric strategy, did not affect performances (transition between stages 1 and 2: days 6-7). During stage 2 (days 7-10), mice of both genotypes continued to perform equally at an asymptotic level of performance: they reached the goal within 10 sec on average, but $\mathrm{KO}$ mice still swam faster than wild-type $(P<0.0001)$. The absence of any difference in performance (as measured by the escape latency and path length) between wildtype and KO during the two first stages of the stepwise protocol, associated with a robust genotype-related change in swim speed, implies that the deletion of the 5-HT1B gene does not, directly or indirectly, interfere with the capacity of mice to locate a fixed hidden platform in the pool when starting from a constant position (stage 1), or to use an allocentric spatial representation for reaching the goal from a new releasing point (stage 2).

The third stage involved no change in the start positions but the relocation of the platform (from the east to the west quadrant; days 11-15). The displacement of the platform (transition between stages 2 and 3 : days 10-11) affected both wild-type and $\mathrm{KO}$ mice, but more critically wild-type performance and swim speed (Fig. 5A,B). During stage 3 (days 11-15), mice learned the new position of the platform, decreasing their latencies across days (Fig. 5A). KO mice learned the new position of the platform more rapidly than wild-type mice $(P<0.01$ for both latency and path length). The swim speed of wild-type mice decreased during this stage of the experiment (Fig. 5B). The fourth and last stage involved an additional (third) new start position (east; days 16-19) that did not change the performance level of the mice (transition between stages 3 and 4). At stage 4 (days 16-19), mice had reached their asymptotic level of performance, but $\mathrm{KO}$ mice showed significantly lower latencies $(P<0.0001)$ and path length $(P=0.025)$, but higher swim speed $(P<0.0001)$ than wild-type mice. In contrast to the results obtained for stages 1 and 2, the 5-HT1BKO mice exhibited a selective facilitation when the task required complex navigational capabilities, for example, after the displacement of the platform (stage 3), and in the multiple starting point version of the task (stage 4; for details, see Wolff et al. 2003a). This ability to use a flexible allocentric strategy to solve these complex spatial tasks is necessary for the establishment of representations of the relations among various distal cues (Eichenbaum 1996) as was the case in our previous study (Malleret et al. 1999). The critical functions of the 5-HT1B receptor in the hippocampus may account for these results. This receptor has, indeed, been identified as controlling the main input and output of the hippocampus: the cholinergic septo-hippocampal pathway (Maura and Raiteri 1986; Cassel et al. 1995) on one side, and the glutamatergic hippocampo-subiculum pathway on the 
other side (Aït Amara et al. 1995, 2001; Boeijinga and Boddeke 1996).

KO and their homologous wild-type mice were subsequently submitted to a 5-d short-term memory (massed) spatial learning version of the water-maze task using eight trials per day across $5 \mathrm{~d}$. Mice improved their performance over successive trials of each daily session as indicated by the escape latencies (Fig. 5C). Wild-type and $\mathrm{KO}$ mice were equally efficient in acquiring this spatial task, despite faster swim speed in $\mathrm{KO}$ than in wild-type mice $(P<0.0001$; Fig. 5D). One of the basic requirements of massed learning is also to use spatial information in a flexible manner, because the platform is displaced from day to day. The discrepancy between the lack of facilitation in this massed learning and the selective increase in efficiency observed in the more complex learning (stages 3 and 4 of the stepwise learning) cannot thus simply describe the facilitation of KO mice in terms of flexibility. It is also clear from the data discussed here (Wolff et al. 2003a) and other results (Contet et al. 2001; Wolff et al. 2002) that "faster is not surer," that is, swim speed is not systematically associated with performance.

Finally, we carried out a replication of our previous experiment using the standard spatial reference memory version of the water maze (discussed above, see also Malleret et al. 1999) with groups of naive adult wild-type and 5-HT1BKO mice to ensure the stability of our previous results obtained three years before (see also Wolff et al. 2003a). In this task, mice decreased their escape latency across days during the acquisition stage (Fig. 5E), but KO mice exhibited shorter latencies $(P=0.0006)$ and swam faster $(P=0.01$; Fig. $5 \mathrm{~F})$ than wild-type mice. After the displacement of the platform (transfer stage), mice learned the new position of the platform, but $\mathrm{KO}$ mice exhibited shorter latencies $(P=0.005)$ and faster swim speed $(P=0.02)$ than wild-type mice. On both the probe trials of the acquisition and transfer stages, all mice exhibited a selective preference for the last position of the platform.

The main conclusion that could be drawn from these data collected across three different studies is that the 5 -HT1B receptor gene deletion selectively enhances learning performance when the cognitive requirement of the task is elevated. This facilitation was not simply caused by a higher swim speed. The shorter path lengths (accuracy) and shorter mean distances of the subject to the platform (spatial strategy) observed in 5-HT1BKO mice clearly assessed better spatial orientation in comparison with wild-type mice, especially during acquisition. The 5-HT1BKO mice displayed better performance than wild-type mice on the more cognitively demanding task (reference memory in the water maze), but no differences between genotypes were observed on less demanding tasks (spontaneous alternation, single startgoal water maze, contextual fear conditioning), as is also the case for other systems involved in hippocampal-dependent memory (Bach et al. 1995). Thus, use of various cognitive tasks, using the same behavioral environment, motivation, and mode of displacement, allowed us to emphasize the link between task difficulty and the effect of the 5-HT1B gene deletion.

\section{The 5-HTIBKO Mouse Exhibits a Selective Delay-Dependent Impairment in a Spatial Working Memory Task in a Radial-Arm Water Maze}

The study detailed in Wolff et al. (2003b) was aimed at evaluating the performance of 5-HT1BKO mice in a spatial working memory task using different retention intervals (RIs) to assess whether the deletion of the 5-HT1B receptor might change the capacity of selective retrieval of trial-unique information, as a function of increasing RIs (delays).

We elaborated a spatial working memory paradigm using a radial-arm water maze, with short, intermediate, and long RIs.
The apparatus was the same shape as a conventional dry radial maze, but the behavioral demand for running into eight diverging arms from a central area was changed into a demand for swimming. A hidden platform was located at the extremity of one arm (called the target arm). During an initial exposure trial, the mouse was forced to reach the designated target arm. During the subsequent test trial, the mouse had to return to that arm without entering into either of two other additional open arms (Fig. 6A). We evaluated the performance of young-adult KO mice in this task, paying particular attention to the level of performance exhibited at various RIs $(0,1,5,60,90 \mathrm{~min})$.

When the mice had reached an asymptotic level of performance on the basic task without delay (Fig. 6B), they were tested with short $(0,1,5 \mathrm{~min})$ and long $(60,90 \mathrm{~min})$ delays. Both wildtype and $\mathrm{KO}$ mice performed equally correctly at short delays. However, 5-HT1B mice exhibited a selective impairment for the 60-min delay, whereas at the 90-min delay all mice failed to recognize the target arm. In a second experiment, we tested the effect of a muscarinic cholinergic antagonist on the protocol in wild-type as well as $\mathrm{KO}$ mice in order to evaluate the existence of a possible interaction between the cholinergic and the serotonergic system, via 5-HT1B receptors. The results showed that treatment with scopolamine $(0.8 \mathrm{mg} / \mathrm{kg}$, i.p. $)$ induced the same pattern of performance in wild type as did the mutation for short (5 min, no impairment) and long (60 min, impairment) delays (Fig. 6C). This indicates the existence of a possible common underlying mechanism of action between cholinergic blockade and 5-HT1B gene deletion.

Compensatory mechanisms in $\mathrm{KO}$ mice might explain part of these results. So far, there are no available data concerning plasticities in the cholinergic system of the 5-HT1BKO mouse. The only findings demonstrate that the basal as well as $\mathrm{K}^{+}$-evoked 5-HT release in the frontal cortex and ventral hippocampus do not differ between wild-type and KO mice (Trillat et al. 1997).

Finally, aged (22-mo-old) KO mice were submitted to the task to evaluate whether the effect of the mutation persists during the aging process as it was observed in the previous hippocampal-dependent model. In addition, we decided to test intermediate delays (15 and $30 \mathrm{~min}$ ) to evaluate more precisely the detrimental effect of the mutation for long RIs. Young-adult $\mathrm{KO}$ mice were found to be impaired at the 60-min delay, confirming our previous results. Moreover, this effect extended to 15- and 30-min delays. Interestingly, this effect of the mutation was also exhibited by aged KO mice. However, we also observed an agerelated decline in performance for the 5- and 15-min delays in both wild-type and $\mathrm{KO}$ mice (Fig. $6 \mathrm{C}$ ). This deficit might result from the predominant control over short-term memory performance by the septo-hippocampal pathway. There indeed exist ample data to support the concept that the hippocampal formation plays a critical functional role in delayed-matching or nonmatching-to-place (e.g., in humans: Eichenbaum et al. 1994; Kesner and Hopkins 2001; in rodents: Eichenbaum et al. 1994; Shen et al. 1996; Steele and Morris 1999; Clark et al. 2001; Johnson et al. 2002). Because several studies have reported the existence of multiple dysfunctions in the hippocampus that are associated with aging, thus affecting various aspects of cognition (for a recent review, see Rosenzweig and Barnes 2003), it is not surprising to observe a more general hippocampal-dependent age-related memory deficit (Barnes and McNaughton 1985; Bach et al. 1999; Foster 1999).

However, this short-delay working memory task did not reveal any significant effect of the mutation. This result contrasts with the facilitatory effect of the mutation in the acquisition of spatial reference memory (see above). The fact that no genotype effect was observed at short delays is consistent with the concept of a hippocampal-dependent control over performance for short-

\section{Learning \& Memory}




\section{Exposure Trial}

A

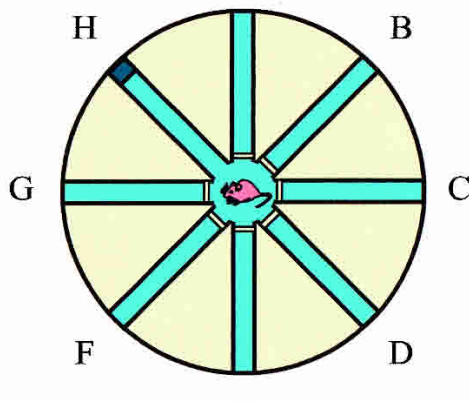

$\mathrm{E}$
A

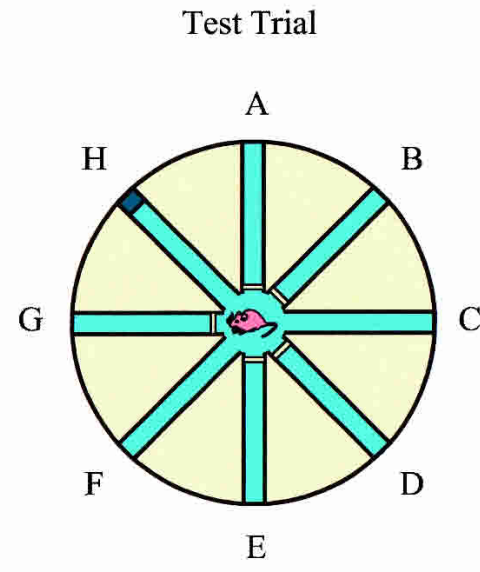

Visit to target arm / total visits B

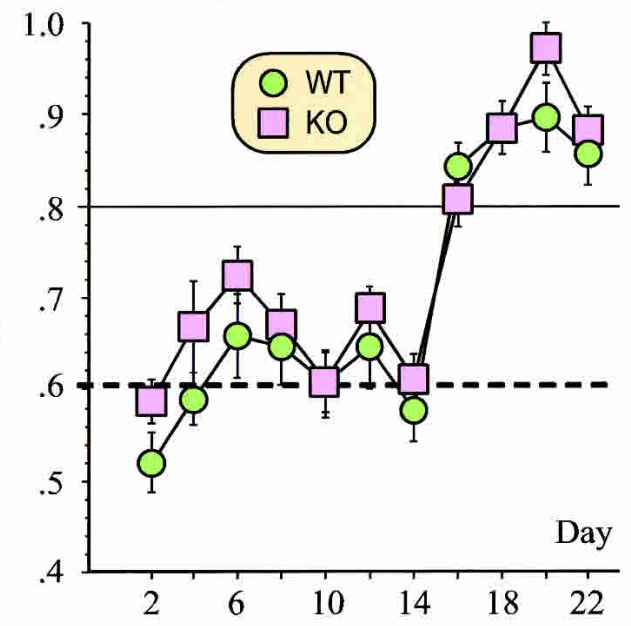

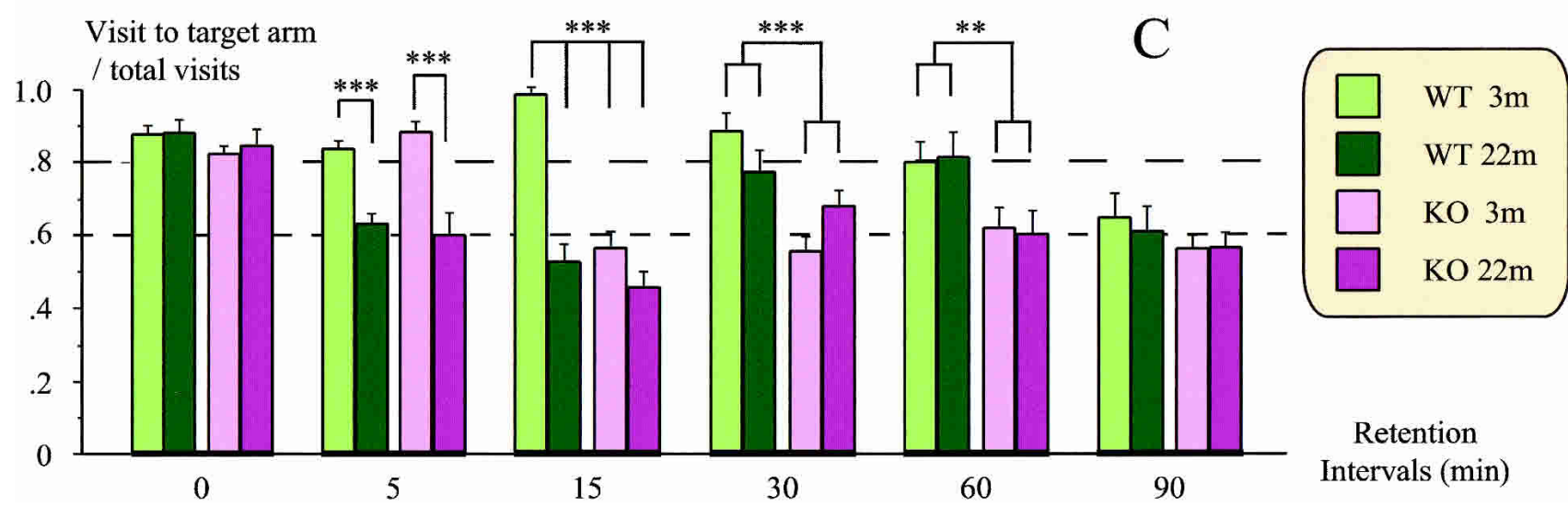

Figure 6 Spatial working memory task. (A) Schematic representation of the protocol. The radial-arm water maze is composed of eight arms (A to $\mathrm{H}$ ) radiating from a central area. During an Exposure Trial, only one arm is available and contains the platform (here, arm $\mathrm{H}$ is the target arm). During a subsequent Test Trial, three arms are available. (B) Performance in basic learning (without delay) of wild-type (WT) and 5-HT1 BKO (KO) mice across days (Day: average measure on two successive days); the performance is evaluated in terms of (visit to the target arm)/(total number of visits). (C) Effect of age on performance at various Retention Intervals: $0,5,15,30,60,90 \mathrm{~min} ;(3 \mathrm{~m}) 3$-mo-old; $(22 \mathrm{~m}) 22$-mo-old; $\left({ }^{\star * *}\right) P<0.0001 ;\left({ }^{* *}\right) P=0.01$. The long-dashed horizontal lines represent the threshold level of performance above chance level; the short-dashed horizontal lines represent performance at chance level (adapted from Wolff et al. 2003b).

to-intermediate (0-5 min) delays (Lee and Kesner 2003). In this case, the lack of facilitation in mutant mice might be caused by a ceiling effect, with all mice reaching an asymptotic level of performance.

The selective impairment of $\mathrm{KO}$ mice at long RIs is more problematic, and raises the possibility that the prefrontal cortex (PFC) may also be required as a second partner to mediate task performance when the RI is long. The medial prefrontal cortex (mPFC) of rodents is, indeed, another brain structure that appears as a good candidate to control working memory functions, such as maintaining information across delays or planning prospective search behavior in spatial tasks (Seamans et al. 1995; Delatour and Gisquet-Verrier 1996, 1999; Granon and Poucet 2000). When the task requires prospective coding of a sequence of several spatial items during a long-term delay (30 min), "the interactive communication between the hippocampus and mPFC might become intensified" (Floresco et al. 1997; see also Lee and Kesner 2003). It was furthermore suggested that a sustained activation of the NBM-cortical cholinergic pathway is re- quired for long retention intervals (longer than 15 min in the mouse) in a spatial working memory task (Durkin 1992). Our results, at least in part, are consistent with such hypotheses.

\section{Concluding Comments}

Taken together, the results of the behavioral studies reported here demonstrate that deletion of the 5 -HT1B receptor produces differential behavioral effects according to the cognitive requirement of the memory task. The posttest durations of cholinergic activation, as measured in mice by using measures of the kinetics of high-affinity choline uptake in the septo-hippocampal and the NBM-cortical pathways, indeed, vary as a function of the type of memory tested (Durkin and Toumane 1992). A plausible hypothesis for explaining the functional dissociation of the mutation might rely on the interaction between the 5-HT1B receptor and ACh release. In the hippocampus, the 5-HT1B receptor inhibits the release of ACh (Izumi et al. 1994; Cassel et al. 1995), thus its inactivation, mimicked by the 5-HT1BKO mouse, might result in hippocampal-dependent learning facilitation. In contrast, stimu- 
lation of the 5-HT1B receptor in the frontal cortex results in an increase in ACh release in this structure (Consolo et al. 1996). This last mechanism might contribute to the selective impairment exhibited by 5-HT1BKO mice, whatever their age, when a long retention interval (equal or superior to 15 -min delay) is required.

The cognitive requirements of the spatial reference memory task are quite different from those of the spatial working memory task using the radial water maze. Schematically, the former task, with repeated exposure to the same spatial information (fixed platform location), basically requires memory consolidation. In contrast, the working memory task requires the selective retrieval of the trial-unique information and, as such, the memory demand is of the "anticonsolidation" type (Laroche et al. 2000). The massed learning protocol we used involves both working and reference memory components in that a new platform location is used each day (working memory component from trial 1 to 2 , each day), but the same position persists across daily additional trials (reference memory component, from trial 2 to 6 or 8 ). The stepwise learning protocol allowed us to also evaluate performance in terms of reference memory while the complexity of the task increased.

Acquisition, consolidation, and retrieval of an invariant long-term information were assessed in the reference memory task, which also demonstrated a facilitation in acquisition of the task by the 5-HT1BKO mouse. The stepwise learning protocol was used as an attempt to dissect the nature of this facilitation. The results showed that $\mathrm{KO}$ mice exhibited facilitation when the difficulty of the task increased. A short-term massed learning protocol that involves both working and reference memory components did not as consistently reveal such a facilitation. Finally, we used a working memory task that allowed us to measure both the rates of acquisition and forgetting, a task that appears to be closer to those used in humans. This was rendered possible by using a spatial recognition protocol in which the information to be retained was only of value for a given trial. The use of variable retention intervals over a wide time window $(0,1,5,15,30,60$, $90 \mathrm{~min}$ ) allowed a fine manipulation of interfering factors over time. The results revealed a selective impairment in 5-HT1BKO mice at long delays that might be related to the opposite role played by the 5 -HT1B receptor on ACh release in the frontal cortex as compared with its role in the hippocampus (Fig. 7).

The next step of this behavioral approach to $\mathrm{KO}$ mice will be to extend the study by using a psychopharmacological strategy, allowing the use of intracerebral microinjection (intra-hippocampal and intra-PFC) of 5-HT1B selective antagonists in behaving mice, with the possibility of also including a microdialysis methodology.

This review was aimed at demonstrating that it is important to combine neurobiological knowledge and behavioral approaches to evaluate the mechanism of action of a specific neurotransmitter receptor in the central nervous system. Conse- quently, the choice of the particular behavioral protocol becomes decisive.

\section{Perspectives: New Tools for Research and Therapeutical Strategies}

The practical applications of this research correspond to the crucial present need to attempt to defer age-related memory decline or to prevent the behavioral consequences of premature serious neuropathologies such as AD. Our insights into the mechanisms by which the cross-talk between 5-HT and ACh signaling occurs, in particular via the mediation of specific types or subtypes of 5-HT receptors, may provide a useful framework for the development of novel drugs to delay or prevent memory decline. Through the development of more specific tools, both pharmacology and molecular biology will contribute to a better understanding of the functions of 5-HT receptor subtypes. These tools will include new selective antagonists and agonists, as well as the ability to target changes in genes at specific times, for example, to bypass the developmental compensatory mechanisms and at specific anatomical sites (e.g., Malleret et al. 2001). However, the behavioral tools will, in all experiments, be decisive. It is thus also crucial to use "targeted" behavioral models to recruit pref-

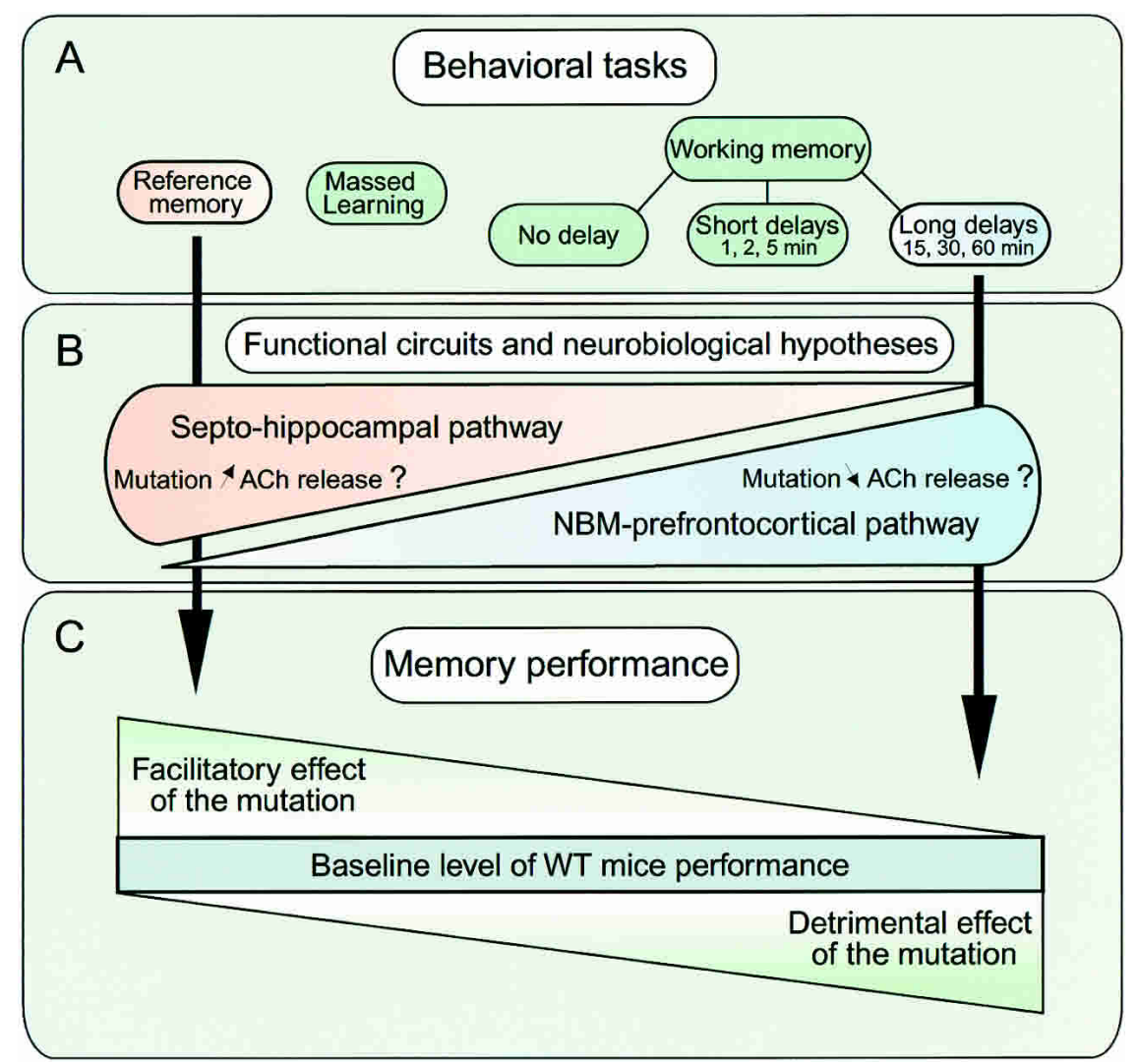

Figure 7 Schematic representation of the main results and hypotheses drawn from the study of the 5HT1BKO mouse. (A) Behavioral tasks. (B) Functional circuits and neurobiological hypotheses. The septo-hippocampal and the NBM-prefrontocortical pathways are thought to be differentially involved depending on the cognitive requirement of the task. As a result of the inactivation of the 5HT1B receptor, the mutation might (? on the figure) be associated with an increase in acetylcholine (ACh) release in the septo-hippocampal pathway and a decrease in the NBM-prefrontocortical pathway. (C) The mutation resulted in changes in memory performance depending on the cognitive demand of the task. A major involvement of the septo-hippocampal pathway might be associated with a facilitatory effect ( $\downarrow$ on left). A major involvement of the NBM-prefrontocortical pathway might be associated with a detrimental effect ( $\downarrow$ on right). In cases of ambiguous or a lack of clear genotype effect, the relationships between the three levels $A, B$, and $C$ is uncertain; consequently it is not represented by a vertical arrow. $(\boldsymbol{x})$ Increases; $(\boldsymbol{x})$ decreases.

\section{Learning \& Memory}


erentially specific neuronal circuits, and thus to increase our knowledge about memory systems.

The behavioral dissociation observed in 5-HT1BKO mice illustrates this requirement and highlights the problem of the potential existence of global "memory enhancers" per se. If there are good reasons to suspect that a given receptor may have different functions in different neuroanatomical structures underlying different cognitive processes, it is clear that activation or inactivation of this receptor will not equally result in the same consequences on memory performance according to the targeted cerebral structure, and even to its linkage to second messengers that may be region- or tissue-specific. In this same context, it has been reported that activation of cAMP-dependent protein kinase A (PKA) in the hippocampus is necessary for long-term memory consolidation because genetic or pharmacological inhibition of PKA disrupts this performance as well as LTP (Abel et al. 1997; Bernabeu et al. 1997). In contrast, activation of the PKA pathway in the prefrontal cortex impairs delayed alternation performance (Taylor et al. 1999).

Thus, besides a consideration of specific memory systems, chemical neurotransmitters, and related receptors, the regional tissue-dependent signal transduction events should also be investigated to aid our progress in the knowledge of the complex mechanisms underlying learning and memory functions.

\section{ACKNOWLEDGMENTS}

This research was supported by the Centre National de la Recherche Scientifique and Université de Bordeaux 1. We thank T.P. Durkin for linguistic corrections of this manuscript and helpful discussions, M. Chaigniau for illustrations, Laboratoire de Transgénèse (Pr. J.-Y. Daniel) and D. Panzeri for their help in animal breeding and care, T. Lafon for his technical assistance with computers, and Pebeo for the generous supply of paint used for watermaze testing. The authors also acknowledge anonymous referees for their help in improving an earlier version of the manuscript. Part of these results were presented at the Fifth IUPHAR Satellite Meeting on Serotonin, July 3-5, 2002, in Acapulco, Mexico.

\section{REFERENCES}

Abel, T., Nguyen, P.V., Barad, M., Deuel, T.A., Kandel, E.R., and Bourtchouladze, R. 1997. Genetic demonstration of a role for PKA in the late phase of LTP and in hippocampus-based long-term memory. Cell 88: 615-626.

Aït Amara, D., Segu, L., Naïli, S., and Buhot, M.-C. 1995. Serotonin 1B receptor regulation after dorsal subiculum deafferentation. Brain Res. Bull. 38: 17-23.

Aït Amara, D., Segu, L., and Buhot, M.-C. 2001. Region-specific decrease in 5-HT1A and 5-HT1B binding sites after intra-hippocampal ibotenic acid injections in the rat. Neurosci. Lett. 310: 25-28.

Albert, P.R., Sajedi, N., Lemonde, S., and Ghahremani, M.H. 1999. Constitutive $\mathrm{G}(\mathrm{i} 2)$-dependent activation of adenylyl cyclase type II by 5 -HT1A receptor. Inhibition by anxiolytic partial agonists. J. Biol. Chem. 274: 35469-35474.

Auld, D.S., Kornecook, T.J., Bastanietto, S., and Quirion, R. 2002. Alzheimer's disease and the basal forebrain cholinergic system: Relations to $\beta$-amyloid peptides, cognition, and treatment strategies. Prog. Neurobiol. 68: 209-245.

Azmitia, E.C. and Segal, M. 1978. An autoradiographic analysis of the differential ascending projections of the dorsal and median raphe nuclei in the rat. J. Comp. Neurol. 179: 641-667.

Bach, M.E., Hawkins, R.D., Osman, M., Kandel, E.R., and Mayford, M. 1995. Impairment of spatial but not contextual memory in CaMKII mutant mice with a selective loss of hippocampal LTP in the range of the theta frequency. Cell 81: 905-915.

Bach, M.E., Barad, M., Son, H., Zhuo, M., Lu, Y.L., Shih, R., Mansuy, I., Hawkins, R.D., and Kandel, E.R. 1999. Age-related defects in spatial memory are correlated with defects in the late phase of hippocampal long-term potentiation in vitro and are attenuated by drugs that enhance the cAMP signaling pathway. Proc. Natl. Acad. Sci. 96: $5280-5285$.

Baddeley, A. 1995. Working memory. In The cognitive neurosciences (ed. M.S. Gazzaniga), pp. 755-764. MIT Press, Cambridge, MA.

Balse, E., Lazarus, C., Kelche, C., Jeltsch, H., Jackisch, R., and Cassel,
J.-C. 1999. Intrahippocampal grafts containing cholinergic and serotonergic fetal neurons ameliorate spatial reference but not working memory in rats with fimbria-fornix/cingular bundle lesions. Brain Res. Bull. 49: 263-272.

Barnes, C.A. and McNaughton, B.L. 1985. An age comparison of the rates of acquisition and forgetting of spatial information in relation to long-term enhancement of hippocampal synapses. Behav. Neurosci. 99: 1040-1048.

Beiko, J., Candusso, L., and Cain, D.P. 1997. The effect of nonspatial water maze pretraining in rats subjected to serotonin depletion and muscarinic receptor antagonism: A detailed behavioural assessment of spatial performance. Behav. Brain. Res. 88: 201-211.

Bernabeu, R., Bevilaqua, L., Ardenghi, P., Bromberg, E., Schmitz, P., Bianchin, M., Izquierdo, I., and Medina, J.H. 1997. Involvement of hippocampal cAMP/cAMP-dependent protein kinase signaling pathways in a late memory consolidation phase of aversively motivated learning in rats. Proc. Natl. Acad. Sci. 94: 7041-7046.

Bockaert, J. and Pin, J.P. 1999. Molecular tinkering of G protein-coupled receptors: An evolutionary success. EMBO J. 18: 1723-1729.

Boeijinga, P.H. and Boddeke, H.W.G.M. 1996. Activation of 5-HT1B receptors suppresses low but not high frequency synaptic transmission in the rat subicular cortex in vitro. Brain Res. 721: 59-65.

Boschert, U., Aït Amara, D., Segu, L., and Hen, R. 1994. The mouse 5-hydroxytryptamine1B receptor is localized predominantly on axon terminals. Neuroscience 58: 167-182.

Boutrel, B., Franc, B., Hen, R., Hamon, M., and Adrien, J. 1999. Key role of 5-HT1B receptors in the regulation of paradoxical sleep as evidenced in 5-HT1B knock-out mice. J. Neurosci. 19: 3204-3212.

Bouwknecht, J.A., Hijzen, T.H., van der Gugten, J., Maes, R.A., Hen, R., and Olivier, B. 2002. 5-HT(1B) receptor knockout mice show no adaptive changes in 5-HT(1A) receptor function as measured telemetrically on body temperature and heart rate responses. Brain Res. Bull. 57: 93-102.

Brezun, J.M. and Daszuta, A. 1999. Depletion in serotonin decreases neurogenesis in the dentate gyrus and the subventricular zone of adult rats. Neuroscience 89: 999-1002.

Brunner, D. and Hen, R. 1997. Insights into the neurobiology of impulsive behavior from serotonin receptor knock out mice. Ann. NY Acad. Sci. 836: 81-105.

Buhot, M.-C. 1997. Serotonin receptors in cognitive behaviors. Curr. Opin. Neurobiol. 7: 243-254.

Buhot, M.-C., Patra, S.K., and Nailli, S. 1995. Spatial memory deficits following stimulation of hippocampal 5-HT1B receptors in the rat. Eur. J. Pharmacol. 285: 221-228.

Buhot, M.-C., Martin, S., and Segu, L. 2000. Role of serotonin in memory impairment. Ann. Med. 32: 210-221.

Buhot, M.-C., Wolff, M., Savova, M., Malleret, G., Hen, R., and Segu, L. 2003a. Protective effect of 5-HT1B receptor gene deletion on the age-related decline in spatial learning abilities in mice. Behav. Brain Res. 142: 135-142.

Buhot, M.-C., Wolff, M., and Segu, L. 2003b. Serotonin. In Memories are made of these: From messengers to molecules. 4. Neurotransmitters and memory formation. I. Principle transmitters (eds. G. Riedel and B. Platt). Landes Bioscience, Georgetown, TX (in press).

Cassel, J.-C. and Jeltsch, H. 1995. Serotonergic modulation of cholinergic function in the central nervous system: Cognitive implications. Neuroscience 69: 1-41.

Cassel, J.-C., Jeltsch, H., Neufang, B., Lauth, D., Szabo, B., and Jackisch, R. 1995. Downregulation of muscarinic- and 5-HT1B-mediated modulation of $\left[{ }^{3} \mathrm{H}\right]$ acetylcholine release in hippocampal slices of rats with fimbria-fornix lesions and intrahippocampal grafts of septal origin. Brain Res. 704: 153-166.

Clark R.E., West, A.N., Zola, S.M., and Squire, L.R. 2001. Rats with lesions of the hippocampus are impaired on the delayed nonmatching-to-sample task. Hippocampus 11: 176-186.

Clifton, P.G., Lee, M.D., Somerville, E.M., Kennett, G.A., and Dourish, C.T. 2003. 5-HT1B receptor knockout mice show a compensatory reduction in 5-HT2C receptor function. Eur. J. Neurosci. 17: 185-190.

Cohen, N.J. 1984. Preserved learning capacity in amnesia: Evidence for multiple memory systems. In Neuropsychology of memory (eds. L.R. Squire and N. Butters), pp. 83-103. Guilford Press, New York.

Cohen, N.J. and Squire, L.R. 1980. Preserved learning and retention of pattern-analysing skill in amnesia: Dissociation of knowing how and knowing that. Science 210: 207-210.

Consolo, S., Arnaboldi, S., Ramponi, S., Nannini, L., Ladinsky, H., and Baldi, G. 1996. Endogenous serotonin facilitates in vivo acetylcholine release in rat frontal cortex through 5-HT1B receptors. J. Pharmacol. Exp. Ther. 277: 823-830.

Contet, C., Rawlins, J.N.P., and Bannerman, D.M. 2001. Faster is not surer-A comparison of C57BL/6J and 129S2/Sv mouse strains in the water maze. Behav. Brain Res. 125: 261-267. 
Delatour, B. and Gisquet-Verrier, P. 1996. Prelimbic cortex specific lesions disrupt delayed-variable response tasks in the rat. Behav. Neurosci. 110: 1282-1298.

. 1999. Lesions of the prelimbic and infralimbic cortices in rats do not disrupt response selection but induce delay-dependent deficits: Evidence for a role in woking memory? Behav. Neurosci.

113: 941-955.

Dulawa, S.C., Hen, R., Scearce-Levie, K., and Geyer, M. 1997. Serotonin $1 \mathrm{~B}$ receptor modulation of startle reactivity, habituation, and prepulse inhibition in wild-type and serotonin 1B knockout mice. Psychopharmacology 132: 125-134.

Durkin, T.P. 1992. Spatial working memory over long retention intervals: Dependence on sustained cholinergic activation in the septohippocampal or nucleus basalis magnocellularis-cortical pathways? Neuroscience 62: 681-693.

Durkin, T.P. and Toumane, A. 1992. Septo-hippocampal and nBM-cortical cholinergic neurones exhibit differential time-courses of activation as a function of both type and duration of spatial memory testing in mice. Behav. Brain Res. 50: 43-52.

Eichenbaum, H. 1996. Is the rodent hippocampus just for 'place.' Curr. Opin. Neurobiol. 6: 187-195.

Eichenbaum, H., Otto, T., and Cohen, N.J. 1994. Two functional components of the hippocampo-memory system. Behav. Brain Sci. 17: 449-518.

Farr, S.A., Uezu, K., Flood, J.F., and Morley, J.E. 1999. Septo-hippocampal drug interactions in post-trial memory processing. Brain Res. 847: 221-230.

Floresco, S.B., Seamans, J.K., and Phillips, A.G. 1997. Selective roles for hippocampal, prefrontal cortical, and ventral striatal circuits in radial-arm maze tasks with or without a delay. J. Neurosci. 17: $1880-1890$.

Foster, T.C. 1999. Involvement of hippocampal synaptic plasticity in age-related memory decline. Brain Res. Rev. 30: 236-249.

Fuster, J.M. 1989. The prefrontal cortex: anatomy, physiology, and neuropsychology of the frontal lobe. Raven Press, New York.

Gallagher, M. and Pelleymounter, M.A. 1988. Spatial learning deficits in old rats: A model for memory decline in the aged. Neurobiol. Aging 9: $549-556$.

Gardier, A.M., David, D.J., Jego, G., Przybylski, C., Jacquot, C., Durier, S., Gruwez, B., Douvier, E., Beauverie, P., Poisson, N., et al. 2003. Effects of chronic paroxetine treatment on dialysate serotonin in 5-HT1B receptor knockout mice. J. Neurochem. 86: 13-24.

Gould, E., Beylin, A., Tanapat, P., Reeves, A., and Shors, T.J. 1999 Learning enhances adult neurogenesis in the hippocampal formation. Nat. Neurosci. 2: 260-265.

Graf, P. and Schacter, D.L. 1985. Implicit and explicit memory for new associations in normal and amnesic patients. J. Exp. Psychol. Learn. Mem. Cogn. 11: 501-518.

Granon, S. and Poucet, B. 1995. Medial prefrontal lesions in the rat and spatial navigation: Evidence for impaired planning. Behav. Neurosci. 109: $474-484$

2000. Involvement of the rat prefrontal cortex in cognitive functions: A central role for the prelimbic area. Psychobiology 28: $229-237$.

Harder, J.A. and Kelly, M.E. 1997. The effect of several putative cognition enhancers on a water maze acquisition deficit induced by pCPA plus scopolamine combination treatment. Pharmacol. Biochem. Behav. 56: 657-661.

Harder, J.A., Kelly, M.E., Cheng, C.H., and Costall, B. 1996. Combined pCPA and muscarinic antagonist treatment produces a deficit in rat water maze acquisition. Pharmacol. Biochem. Behav. 55: 61-65.

Hennevin, E., Hars, B., Maho, C., and Bloch, V. 1995. Processing of learned information in paradoxical sleep: Relevance for memory. Behav. Brain Res. 69: 125-135.

Hoyer, D. and Martin, G.R. 1997. 5-HT receptor classification and nomenclature: Towards a harmonization with the human genome. Neuropharmacology 36: 419-428.

Izumi, J., Washizuka, M., Miura, N., Hiraga, Y., and Ikeda, Y. 1994 Hippocampal serotonin 5-HT1A receptor enhances acetylcholine release in conscious rats. J. Neurochem. 62: 1804-1808.

Johnson, D.A., Zambon, N.J., and Gibbs, R.B. 2002. Selective lesion of cholinergic neurons in the medial septum by 192 IgG-saporin impairs learning in a delayed matching to position T-maze paradigm. Brain Res. 943: 132-141.

Kasa, P., Rakinczay, Z., and Gulya, K. 1997. The cholinergic system in Alzheimer's disease. Prog. Neurobiol. 52: 511-535.

Kesner, R.P. 1986. Neurobiological views of memory. In Learning and memory: a biological view (eds. J.L. Martinez and R.P. Kesner), pp. 399-438. Academic Press, New York.

Kesner, R.P. and Hopkins, R.O. 2001. Short-term memory for duration and distance in humans: Role of the hippocampus. Neuropsychology 15: $58-68$.
Lai, M.K., Tsang, S.W., Francis, P.T., Keene, J., Hope, T., Esiri, M.M., Spence, I., and Chen, C.P. 2002. Postmortem serotoninergic correlates of cognitive decline in Alzheimer's disease. Neuroreport 13: $1175-1178$

Laroche, S., Davis, S., and Jay, T.M. 2000. Plasticity at hippocampal to prefrontal cortex synapses: Dual roles in working memory and consolidation. Hippocampus 10: 438-446.

Lee, I. and Kesner, R.P. 2003. Time-dependent relationship between the dorsal hippocampus and the prefrontal cortex in spatial memory. $J$. Neurosci. 23: 1517-1523.

Lee, M.D. and Simansky, K.J. 1997. CP-94,253: A selective serotonin1B (5-HT1B) agonist that promotes satiety. Psychopharmacology 131: $264-270$.

Le Grand, B., Panissie, A., Pauwels, P.J., and John, G.W. 1998. Activation of recombinant h5-HT1B and h5-HT1D receptors stably expressed in C6 glioma cells produces increases in $\mathrm{Ca}^{2+}$-dependent $\mathrm{K}^{+}$current. Naunyn Schmiedebergs Arch. Pharmacol. 358: 608-615.

Lehmann, O., Jeltsch, H., Lehnardt, O., Pain, L., Lazarus, C., and Cassel, J.-C. 2000. Combined lesions of cholinergic and serotonergic neurons in the rat brain using 192 IgG-saporin and

5,7-dihydroxytryptamine: Neurochemical and behavioural characterization. Eur. J. Neurosci. 12: 67-79.

Lehmann, O., Jeltsch, H., Lazarus, C., Tritschler, L., Bertrand, F., and Cassel, J.-C. 2002. Combined 192 IgG-saporin and 5,7-dihydroxytryptamine lesions in the male rat brain: A neurochemical and behavioral study. Pharmacol. Biochem. Behav. 72: 899-912.

Lindner, M.D., Balch, A.H., and VanderMaelen, C.P. 1992. Short forms of the "reference" and "working-memory" Morris water maze for assessing age-related deficits. Behav. Neural Biol. 58: 94-102.

Malleret, G., Hen, R., Guillou, J.-L., Segu, L., and Buhot, M.-C. 1999. 5-HT1B receptor knock-out mice exhibit increased exploratory activity and enhanced spatial memory performance in the Morris water maze. J. Neurosci. 19: 6157-6168.

Malleret, G., Haditsch, U., Genoux, D., Jones, M.W., Bliss, T.V., Vanhoose, A.M., Weitlauf, C., Kandel, E.R., Winder, D.G., and Mansuy, I.M. 2001. Inducible and reversible enhancement of learning, memory, and long-term potentiation by genetic inhibition of calcineurin. Cell 104: 675-686.

Mamounas, L.A., Mullen, C.A., O'Hearn, E., and Molliver, M.E. 1991. Dual serotoninergic projections to forebrain in the rat: Morphologically distinct 5-HT axon terminals exhibit differential vulnerability to neurotoxic amphetamine derivatives. J. Comp. Neurol. 314: 558-586.

Marinissen, M.J. and Gutkind, J.S. 2001. G-protein-coupled receptors and signaling networks: Emerging paradigms. Trends Pharmacol. Sci. 22: $368-376$.

Markowska, A.L. and Wenk, G.L. 1991. Serotonin influences the behavioral recovery of rats following nucleus basalis lesions. Pharmacol. Biochem. Behav. 38: 731-737.

Maura, G. and Raiteri, M. 1986. Cholinergic terminals in rat hippocampus possess 5-HT1B receptors mediating inhibition of acetylcholine release. Eur. J. Pharmacol. 129: 333-337.

Meltzer, C.C., Smith, G., DeKosky, S.T., Pollock, B.G., Mathis, C.A., Moore, R.Y., Kupfer, D.J., and Reynolds, C.F. 1998. Serotonin in aging, late-life depression, and Alzheimer's disease: The emerging role of functional imaging. Neuropsychopharmacology 18: 407-430.

Milner, T.A. and Veznedaroglu, E. 1993. Serotonin-containing terminals synapse on septohippocampal neurons in the rat. J. Neurosci. Res. 36: 260-271.

Morris, R. 1984. Development of a water-maze procedure for studying spatial learning in the rat. J. Neurosci. Meth. 11: 47-60.

O'Keefe, J. and Nadel, L. 1978. The hippocampus as a cognitive map. Clarendon Press, Oxford, UK.

Olton, D., Becker, J., and Handelmann, G. 1979. Hippocampus, space, and memory. Behav. Brain Sci. 2: 313-365.

Perez-Vega, M.I., Feria-Velasco, A., and Gonzalez-Burgos, I. 2000. Prefrontocortical serotonin depletion results in plastic changes of prefrontocortical pyramidal neurons, underlying a greater efficiency of short-term memory. Brain Res. Bull. 53: 291-300.

Ramboz, S., Saudou, F., Aït Amara, D., Belzung, C., Segu, L., Misslin, R., Buhot, M.-C., and Hen, R. 1996. 5-HT1B receptor knock out-Behavioral consequences. Behav. Brain Res. 73: 305-312.

Richter-Levin, G. and Segal, M. 1993. Age-related cognitive deficits in rats are associated with a combined loss of cholinergic and serotonergic functions. Ann. NY Acad. Sci. 695: 254-257.

Rocha, B.A., Scearce-Levie, K., Lucas, J.J., Hirio, N., Castanon, N., Crabbe, J.C., Nestler, E.J., and Hen, R. 1998. Increased vulnerability to cocaine in mice lacking the serotonin-1B receptor. Nature 393: $175-178$

Rosenzweig, E.S. and Barnes, C.A. 2003. Impact of aging on hippocampal function: Plasticity, network dynamics, and cognition.

\section{Learning \& Memory}


Prog. Neurobiol. 69: 143-179.

Sari, Y., Lefèvre, K., Bancila, M., Quignon, M., Miquel, M.C., Langlois, X., Hamon, M., and Verge, D. 1997. Light and electron microscopic immunocytochemical visualization of 5-HT1B receptors in the rat brain. Brain Res. 760: 281-286.

Saudou, F., Aït Amara, D., Dierich, A., LeMeur, M., Ramboz, S., Segu, L., Buhot, M.-C., and Hen, R. 1994. Enhanced aggressive behavior in mice lacking 5-HT1B receptor. Science 265: 1875-1878.

Seamans, J.K., Floresco, S.B., and Phillips, A.G. 1995. Functional differences between the prelimbic and anterior cingulate regions of the rat prefrontal cortex. Behav. Neurosci. 109: 1063-1073.

Shen, J., Barnes, C.A., Wenk, G.L., and McNaughton, B.L. 1996 Differential effects of selective immunotoxic lesions of medial septal cholinergic cells on spatial working and reference memory. Behav. Neurosci. 110: 1181-1186.

Shors, T.J., Townsend, D.A., Zhao, M., Kozorovitsky, Y., and Gould, E. 2002. Neurogenesis may relate to some but not all types of hippocampal-dependent learning. Hippocampus 12: 578-584.

Sirvio, J. 1999. Strategies that support declining cholinergic neurotransmission in Alzheimer's disease patients. Gerontology $\mathbf{4 5}$ suppl. 1: $3-14$.

Steckler, T. and Sahgal, A. 1995. The role of serotonergic-cholinergic interactions in the mediation of cognitive behaviour. Behav. Brain Res. 67: 165-199.

Steele, R.J. and Morris, R.G.M. 1999. Delay-dependent impairment of a matching-to-place task with chronic and intrahippocampal infusion of the NMDA-antagonist D-AP5. Hippocampus 9: 118-136.

Taylor, J.R., Birnbaum, S., Ubriani, R., and Arnsten, A.F.T. 1999. Activation of cAMP-dependent protein kinase A in prefrontal cortex impairs working memory performance. J. Neurosci. 19 (RC23): 1-5.

Trillat, A.C., Malagie, I., Scearce, K., Pons, D., Anmella, M.C., Jacquot, C., Hen, R., and Gardier, A.M. 1997. Regulation of serotonin release in the frontal cortex and ventral hippocampus of homozygous mice lacking 5-HT1B receptors: In vivo microdialysis studies. J. Neurochem. 69: 2019-2025.

Tulving, E. 1987. Multiple memory systems and consciousness. Hum. Neurobiol. 6: 67-80.

1991. Concepts of human memory. In Memory: Organization and locus of change (eds. L.R. Squire et al.), pp. 3-32. Oxford University Press, Oxford, U.K.

Tune, L.E. and Sunderland, T. 1998. New cholinergic therapies: Treatment tools for the psychiatrist. J. Clin. Psych. 59 suppl. 13: $31-35$.

van der Staay, F.J. 2002. Assessment of age-associated cognitive deficits in rats: A tricky business. Neurosci. Biobehav. Rev. 26: 753-759.

Vanderwolf, C.H., Leung, L.W.S., Baker, G.B., and Stewart, D.J. 1989. The role of serotonin in the control of cerebral activity: Studies with intracerebral 5,7-dihydroxytryptamine. Brain Res. 504: 181-191.

Wilson, M.A. and Molliver, M.E. 1991. The organization of serotonergic projection to cerebral cortex in primates: Retrograde transport studies. Neuroscience 44: 555-570.

Wolff, M., Savova, M., Malleret, G., Segu, L., and Buhot, M.-C. 2002. Differential learning abilities of 129T2/Sv and C57BL/6J mice as assessed in three water maze protocols. Behav. Brain Res. 136: $463-474$.

Wolff, M., Savova, M., Malleret, G., Hen, R., Segu, L., and Buhot, M.-C. 2003a. Serotonin knockout mice exhibit a task-dependent selective learning facilitation. Neurosci. Lett. 338: 1-4.

Wolff, M., Benhassine, N., Costet, P., Hen, R., Segu, L., and Buhot, M.-C. 2003b. Delay-dependent working memory impairment in young-adult and aged 5-HT1BKO mice as assessed in a radial-arm water maze. Learn. Mem. 10: 401-409.

Zgombick, J.M. and Branchek, T.A. 1998. Native 5-HT1B receptors expressed in OK cells display dual coupling to elevation of intracellular calcium concentrations and inhibition of adenylate cyclase. Naunyn Schmiedebergs Arch. Pharmacol. 358: 503-508. 


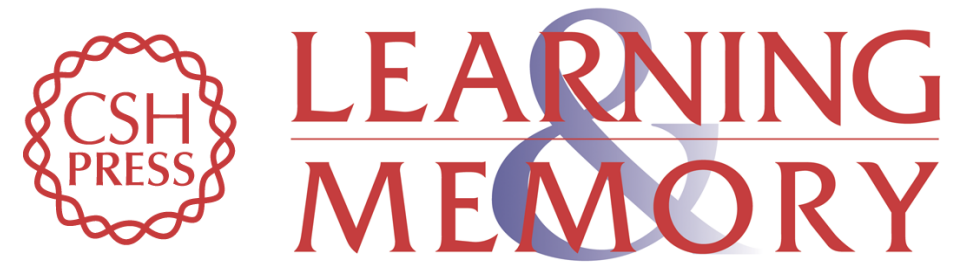

\section{Spatial Learning in the 5-HT1B Receptor Knockout Mouse: Selective Facilitation/Impairment Depending on the Cognitive Demand}

Marie-Christine Buhot, Mathieu Wolff, Narimane Benhassine, et al.

Learn. Mem. 2003, 10:

Access the most recent version at doi:10.1101//m.60203

References This article cites 94 articles, 13 of which can be accessed free at: http://learnmem.cshlp.org/content/10/6/466.full.html\#ref-list-1

License

Email Alerting Receive free email alerts when new articles cite this article - sign up in the box at the Service top right corner of the article or click here. 